\title{
Article \\ Epigallocatechin-3-Gallate Modulates Postoperative Pain by Regulating Biochemical and Molecular Pathways
}

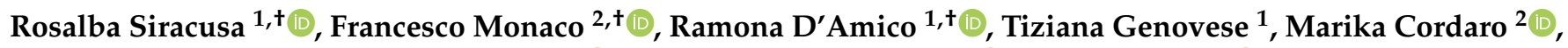 \\ Livia Interdonato ${ }^{1}$, Enrico Gugliandolo ${ }^{3}{ }^{(\mathcal{D}}$, Alessio Filippo Peritore ${ }^{1}{ }^{1}$, Rosalia Crupi ${ }^{3}{ }^{\circledR}$, Salvatore Cuzzocrea ${ }^{1}{ }^{1}$, \\ Daniela Impellizzeri ${ }^{1, *} * \mathbb{D}$, Roberta Fusco ${ }^{1, \neq(1)}$ and Rosanna Di Paola ${ }^{1, \neq(1)}$
}

1 Department of Chemical, Biological, Pharmaceutical and Environmental Sciences, University of Messina, 98168 Messina, Italy; rsiracusa@unime.it (R.S.); rdamico@unime.it (R.D.); tgenovese@unime.it (T.G.); livia.interdonato@yahoo.it (L.I.); aperitore@unime.it (A.F.P.); salvator@unime.it (S.C.); rfusco@unime.it (R.F.); dipaolar@unime.it (R.D.P.)

2 Department of Biomedical, Dental and Morphological and Functional Imaging, University of Messina, 98125 Messina, Italy; fmonaco@unime.it (F.M.); cordarom@unime.it (M.C.)

3 Department of Veterinary Sciences, University of Messina, 98168 Messina, Italy; egugliandolo@unime.it (E.G.); rcrupi@unime.it (R.C.)

* Correspondence: dimpellizzeri@unime.it; Tel.: +39-090-676-5208

+ These authors contributed equally to this work.

$\ddagger$ These authors shared senior authorship.

check for updates

Citation: Siracusa, R.; Monaco, F.; D'Amico, R.; Genovese, T.; Cordaro, M.; Interdonato, L.; Gugliandolo, E.; Peritore, A.F.; Crupi, R.; Cuzzocrea, S.; et al. Epigallocatechin-3-Gallate Modulates Postoperative Pain by Regulating Biochemical and Molecular Pathways. Int. J. Mol. Sci. 2021, 22, 6879. https://doi.org/ $10.3390 /$ ijms 22136879

Academic Editor: Claudiu T. Supuran

Received: 11 June 2021

Accepted: 22 June 2021

Published: 26 June 2021

Publisher's Note: MDPI stays neutral with regard to jurisdictional claims in published maps and institutional affiliations.

Copyright: (c) 2021 by the authors. Licensee MDPI, Basel, Switzerland. This article is an open access article distributed under the terms and conditions of the Creative Commons Attribution (CC BY) license (https:/ / creativecommons.org/licenses/by/ $4.0 /)$.
Abstract: Treating postoperative (PO) pain is a clinical challenge. Inadequate PO pain management can lead to worse outcomes, for example chronic post-surgical pain. Therefore, acquiring new information on the PO pain mechanism would increase the therapeutic options available. In this paper, we evaluated the role of a natural substance, epigallocatechin-3-gallate (EGCG), on pain and neuroinflammation induced by a surgical procedure in an animal model of PO pain. We performed an incision of the hind paw and EGCG was administered for five days. Mechanical allodynia, thermal hyperalgesia, and motor dysfunction were assessed $24 \mathrm{~h}$, and three and five days after surgery. At the same time points, animals were sacrificed, and sera and lumbar spinal cord tissues were harvested for molecular analysis. EGCG administration significantly alleviated hyperalgesia and allodynia, and reduced motor disfunction. From the molecular point of view, EGCG reduced the activation of the WNT pathway, reducing WNT3a, cysteine-rich domain frizzled (FZ)1 and FZ8 expressions, and both cytosolic and nuclear $\beta$-catenin expression, and the noncanonical $\beta$-cateninindependent signaling pathways, reducing the activation of the NMDA receptor subtype NR2B (pNR2B), pPKC and cAMP response element-binding protein (pCREB) expressions at all time points. Additionally, EGCG reduced spinal astrocytes and microglia activation, cytokines overexpression and nuclear factor kappa-light-chain-enhancer of activated B cells (NFkB) pathway, downregulating inducible nitric oxide synthase (iNOS) activation, cyclooxygenase 2 (COX-2) expression, and prostaglandin E2 (PGE2) levels. Thus, EGCG administration managing the WNT/ $\beta$-catenin signaling pathways modulates PO pain related neurochemical and inflammatory alterations.

Keywords: pain; epigallocat-echin-3-gallate; rat

\section{Introduction}

In recent years, the undertreatment of acute pain was identified as a major health-care concern. Clinical analysis showed that only the $25 \%$ of surgical patients had satisfactory relief of acute pain [1]. Despite significant improvements in pain management, researchers suggest that postoperative (PO) pain is still inadequately managed [2,3]. The lack of a clinically meaningful progress in the PO pain analgesia is probably due to the limited efficacy and side effects of the available analgesic drugs [4,5]. Treatment of $\mathrm{PO}$ pain continues to be an important clinical goal. It is of fundamental importance to discover the mechanisms underlying PO pain, as well as to find medications to treat it. Despite numerous 
implicated processes and decades of investigation, the molecular and cellular mechanisms underlying $\mathrm{PO}$ pain remain uncertain, and therapeutic approaches for managing $\mathrm{PO}$ pain are limited. It has been described that central neuronal sensitization is involved in PO pain and hyperalgesia [6,7]. In vivo neurological studies have displayed increased rates and prevalence of spontaneous activity of spinal neurons in the dorsal horn after surgery $[8,9]$. However, the complete role of central sensitization in the pathophysiology of persistent $\mathrm{PO}$ pain is elusive [9]. A rat model for PO pain has been characterized by Brennan et al. [10]. In particular, the model consists of a surgical incision in the plantar hind paw and is characterized by enhanced responsiveness to mechanical stimuli [11]. At the end of the surgery, after the recovery from anesthesia, the allodynia and the reduced withdrawal thresholds are maxima and remains significant for several days before progressively decreasing [12]. Thus, investigating the role of the spinal activation in the perception and persistence of $\mathrm{PO}$ pain is an important challenge. It has been reported that the neuronal alterations that occur in neuropathic and bone cancer pain involve the activation of the WNT signaling [13].

WNTs are a family of proteins serving as long- or short-range signaling mediators in the management of cellular processes, such as differentiation, proliferation, and migration, during the development of the cardiac and central nervous system [14,15]. In humans, 19 members of these secreted lipid-modified signalling proteins have been identified [16]. In particular, WNT pathways include noncanonical $\beta$-catenin-independent signaling pathways and canonical $\beta$-catenin signaling pathways $[14,17-20]$. In the canonical pathway, WNT ligands link to the cysteine-rich domain frizzled (FZ) receptors which, in turn, activate several intracellular signaling cascades, including pro-inflammatory events. $\beta$-Catenin is a multi-purpose protein that interrelates with transcription factors to induce target gene transcription. The noncanonical $\beta$-catenin-independent signaling pathways consist in the release of intracellular calcium and the activation of the subsequent intracellular pathways $[19,21]$. Therefore, we imagined that targeting the WNT pathways with natural small molecules without side effects that would interfere with the analgesic drugs may be an effective strategy to counteract $\mathrm{PO}$ pain.

Green tea has anti-inflammatory, anti-oxidant, anti-diabetic, and hypolipidemic effects. It increases insulin glucose uptake and insulin activity and reduces glucose absorption [22]. Moreover, green tea has a positive outcome in cases of cardiovascular diseases, cancer, oxidative stress, neurological diseases, infections, and hypercholesterolemia [23-27]. One of the most abundant active substances (up to 63\%) in green tea is the epigallocatechin-3gallate (EGCG) [28]. It has important activities, such as anti-oxidant, hypolipidemic, antiinflammatory, anti-obesity, anticancer, and antidiabetic $[29,30]$. It shows an inhibitory effect on the WNT/ $\beta$-catenin signaling pathways in human osteoarthritis chondrocytes [31]. The aim of this study was to evaluate the effect of the EGCG on the perception and persistence at different days of $\mathrm{PO}$ pain through the modulation of the canonical and noncanonical $\beta$-cateninindependent WNT signaling pathways, neurochemical and inflammatory modifications.

\section{Results}

2.1. Effect of EGCG Administration on Mechanical Allodynia, Thermal Hyperalgesia, and Motor Dysfunction Induced by PO Pain

Behavioral analyses were performed in order to evaluate EGCG effect on pain perception. Mechanical allodynia (Figure 1A) and thermal hyperalgesia (Figure 2B) strongly increased already after two hours from surgical incision and lasted for five days gradually decreasing. EGCG administration already after 24 hours and three days increased the response to von Frey stimulation and heat source, reporting animals to pre-surgery levels at day four after surgery. To assess motor function, a rotarod test was performed (Figure 1C). Immediately after the surgery, animals showed impairments in motor coordination and took five days to recover. EGCG treatment significantly improved locomotor activity already after $24 \mathrm{~h}$ and three days from surgery. 

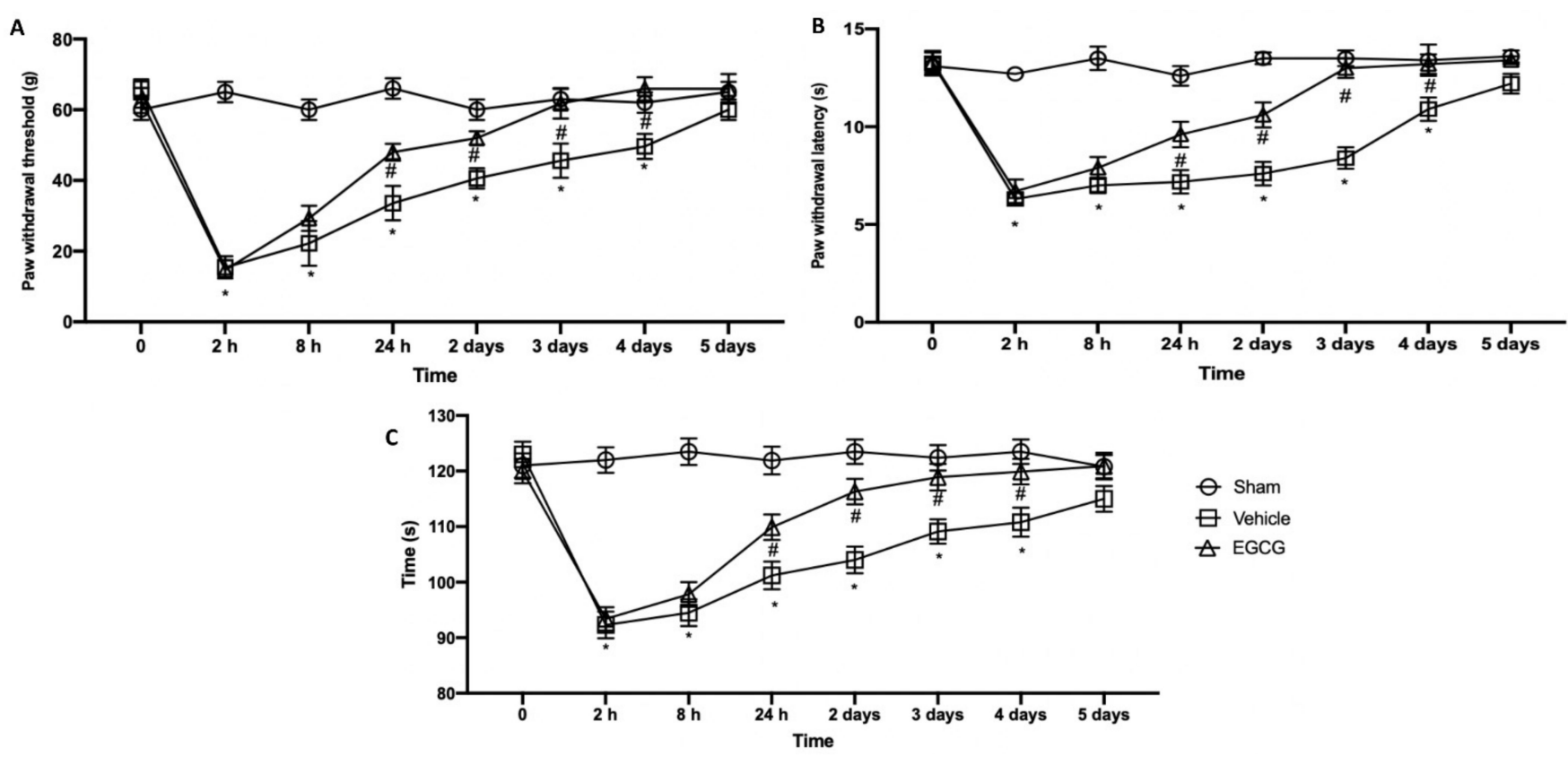

Figure 1. EGCG administration reduced mechanical allodynia, thermal hyperalgesia and motor dysfunction: von Frey test (A), plantar test (B) and rotarod test (C). A $p$-value of less than 0.05 was considered significant. ${ }^{*} p<0.05$ vs. sham, $\# p<0.05$ vs. vehicle.
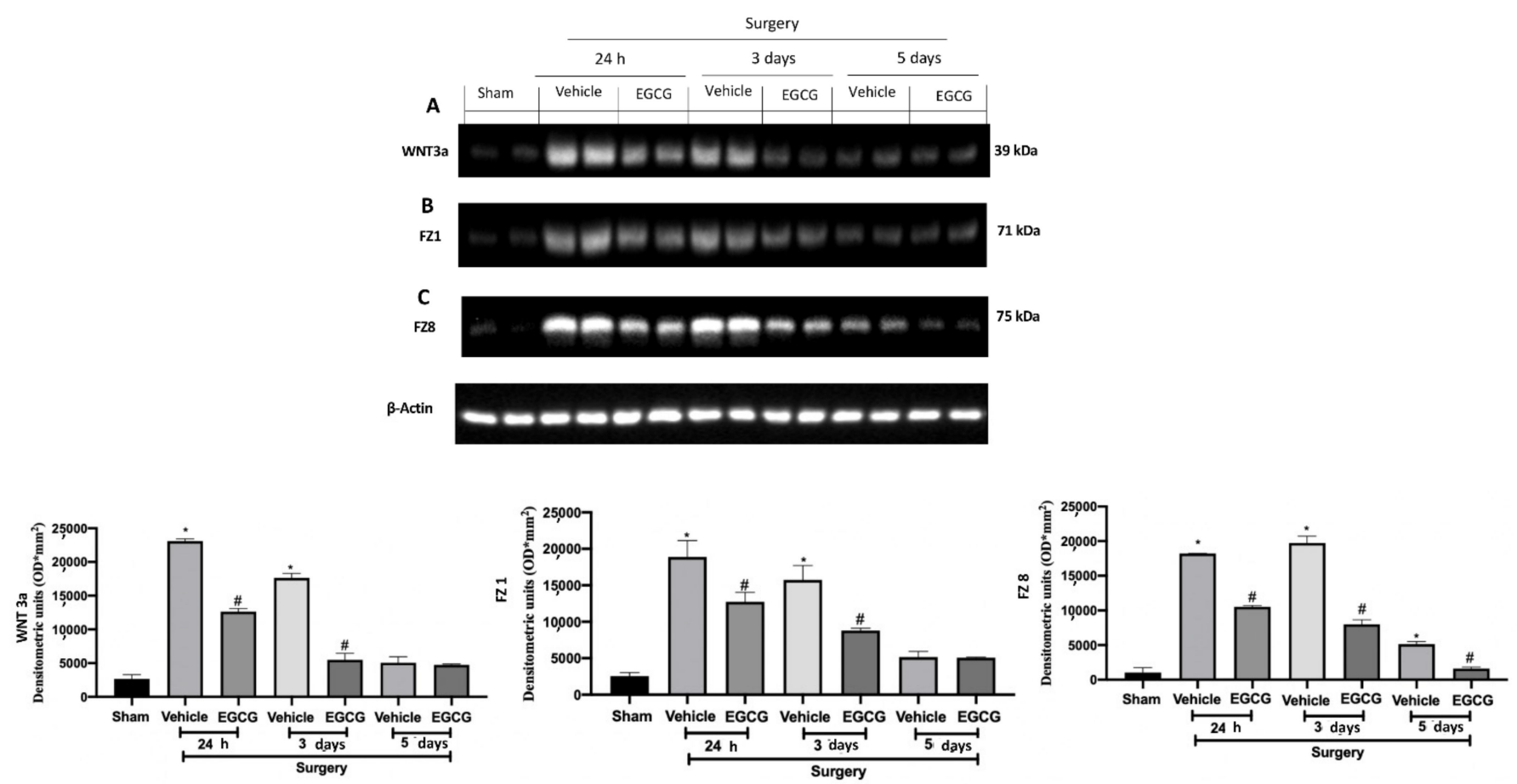

Figure 2. EGCG administration reduced WNT/FZ/ $\beta$-catenin pathway activation: Western blot analysis of: WNT3a (A), FZ1 (B), FZ8 (C) expression. A $p$-value of less than 0.05 was considered significant. ${ }^{*} p<0.05$ vs. sham, $\# p<0.05$ vs. vehicle.

\subsection{Effect of EGCG Administration on WNT/FZ/ $\beta$-Catenin Pathway Activation Induced by PO Pain}

Western blot analysis showed increased WNT3a and FZ1 expression in samples harvested from vehicle treated rats $24 \mathrm{~h}$ and three days after surgery, as compared to sham animals, while no differences were detected at five days. EGCG administration significantly decreased WNT3a and FZ1 expression after $24 \mathrm{~h}$ and restored them to basal levels, three and five days after surgery (Figure 2A,B). FZ8 expression was significantly 
increased at all timepoints ( $24 \mathrm{~h}$, and three and five days) as compared to the sham. EGCG treatment reduced FZ8 expression and restored it to basal levels after five days from surgery (Figure 2C). Additionally, in both cytosolic (Figure 3A) and nuclear (Figure 3B) fractions, $\beta$-catenin expression was significantly increased. EGCG administration strongly reduced $\beta$-catenin expression in cytoplasm and nucleus at all timepoints.
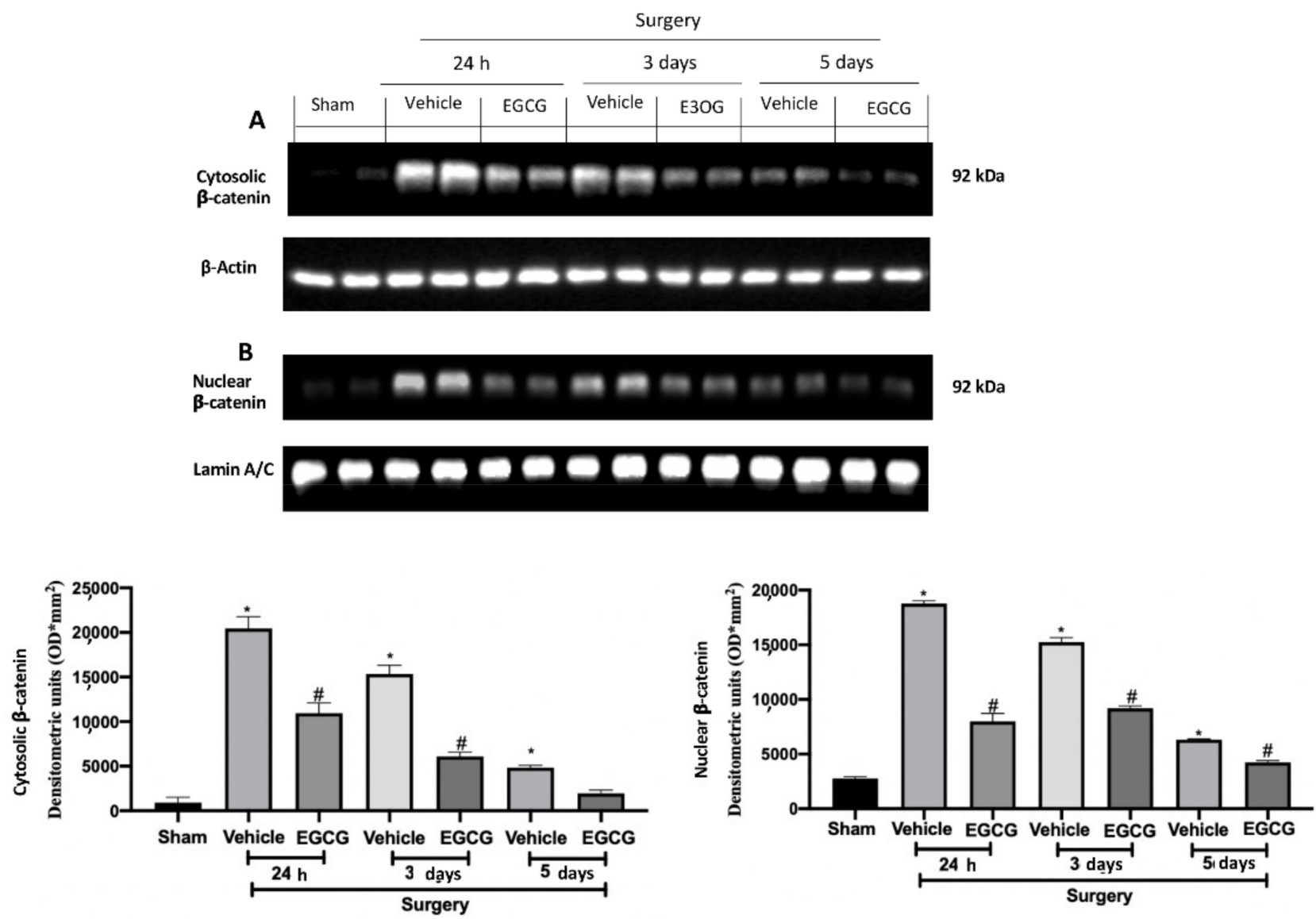

Figure 3. EGCG administration reduced $\beta$-catenin expression: Western blot analysis of: cytosolic $\beta$-catenin (A) and nuclear $\beta$-catenin (B) expression. A $p$-value of less than 0.05 was considered significant. ${ }^{*} p<0.05$ vs. sham, $\# p<0.05$ vs. vehicle.

\subsection{Effect of EGCG Administration on GFAP and Iba-1 Activation Induced by PO Pain}

Immunohistochemical analysis showed activated astrocytes and microglia were detected in vehicle treated rats. In particular, increased GFAP expression in vehicle treated rats at $24 \mathrm{~h}$ (Figure $4 \mathrm{~B}$ ) and three days (Figure $4 \mathrm{D}$ ) after surgery, as compared to sham rats (Figure 4A), while, at five days, small levels of activation was detected (Figure 4F). EGCG administration significantly decreased GFAP expression at all timepoints (Figure 4C,E,G). Moreover, increased Iba-1 expression was found after $24 \mathrm{~h}$ (Figure $4 \mathrm{I}$ ) and three days (Figure $4 \mathrm{~K}$ ), as compared to the sham animals (Figure 4H). Five days after surgery, Iba-1 expression slightly decreased in vehicle group (Figure 4M). EGCG treatment reduced microglia activation $24 \mathrm{~h}$ (Figure $4 \mathrm{~J}$ ), and three (Figure $4 \mathrm{~L}$ ) and five (Figure $4 \mathrm{~N}$ ) days after surgery. 


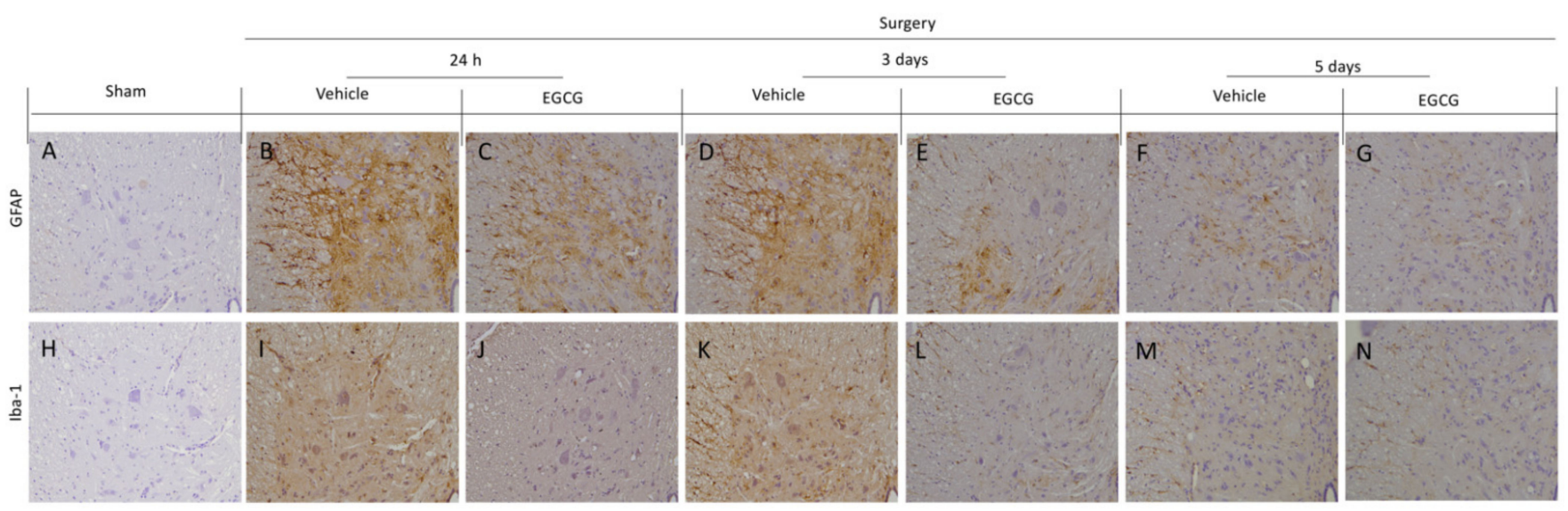

Figure 4. EGCG administration reduced GFAP and Iba-1 activation: Immunohistochemical analysis of GFAP: sham (A), vehicle $24 \mathrm{~h}$ (B), EGCG $24 \mathrm{~h}$ (C), vehicle three days (D), EGCG three days (E), vehicle five days (F), EGCG five days (G). Immunohistochemical analysis of Iba-1: sham (H), vehicle $24 \mathrm{~h}(\mathbf{I})$, EGCG $24 \mathrm{~h}(\mathbf{J})$, vehicle three days (K), EGCG three days (L), vehicle five days (M), EGCG five days (N). A $p$-value of less than 0.05 was considered significant.

\subsection{Effect of EGCG Administration on $p N R 2 B, p P K C \gamma$, and $p C R E B$ Expression Induced by PO Pain}

Western blot analysis showed increased pNR2B expression (Figure $5 \mathrm{~A}$ ), $\mathrm{pPKC} \gamma$ (Figure 5B) and pCREB (Figure 5C) expression in samples harvested from vehicle treated rats $24 \mathrm{~h}$ and three days after surgery, as compared to sham animals, while at five days it slightly decreased. EGCG administration significantly decreased pNR2B (Figure 5A), pPKC $\gamma$ (Figure 5B) and pCREB (Figure 5C) expression after at all timepoints.
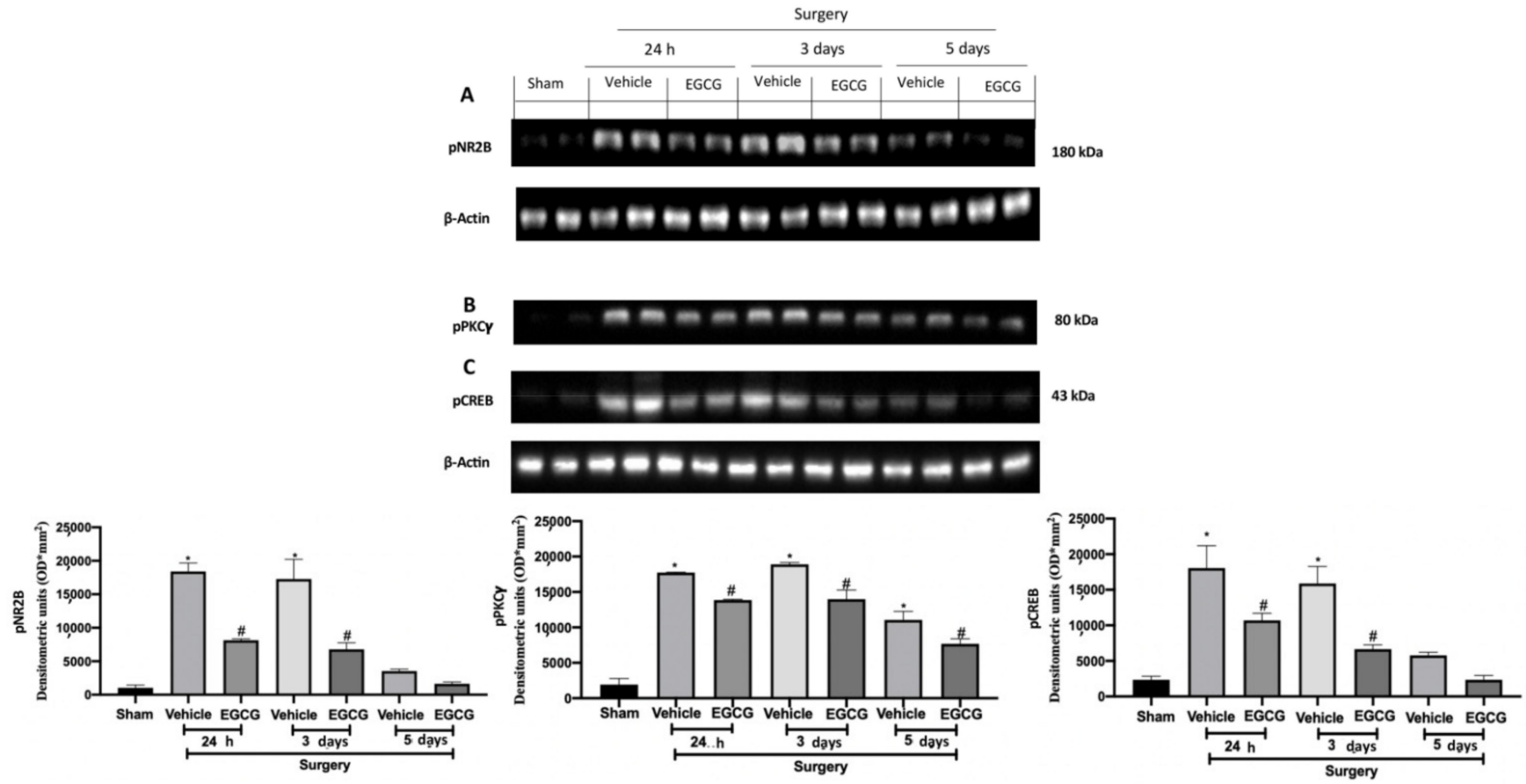

Figure 5. EGCG administration reduced pNR2B, pPKC $\gamma$ and pCREB expression: Western blot analysis of: pNR2B (A), pPKC $\gamma(\mathbf{B})$, pCREB (C) expression. A $p$-value of less than 0.05 was considered significant. ${ }^{*} p<0.05$ vs. sham, $\# p<0.05$ vs. vehicle. 


\subsection{Effect of EGCG Administration on Cytokines and NFkB Pathway Activation Induced by PO Pain}

Increased levels of IL-18 (Figure 6A), TNF- $\alpha$ (Figure 6B) and IL-1 $\beta$ (Figure 6C) were detected in the vehicle group $24 \mathrm{~h}$, and three and five days from surgery. EGCG treatment strongly reduced their expression, restoring it to basal levels at five days. Western blot analysis showed reduced IkB- $\alpha$ expression in the cytosolic fraction of the samples harvested from the vehicle group at all timepoints, as compared to the sham (Figure 6D). EGCG administration increased cytosolic IkB- $\alpha$ expression at $24 \mathrm{~h}$ and three days from surgery and restored it to basal levels after five. In the nuclear fraction, NFkB expression was increased in the vehicle group at all timepoints, as compared to the sham animals (Figure 6E). EGCG treatment significantly reduced nuclear NFkB expression at $24 \mathrm{~h}$, and three and five days from surgery.
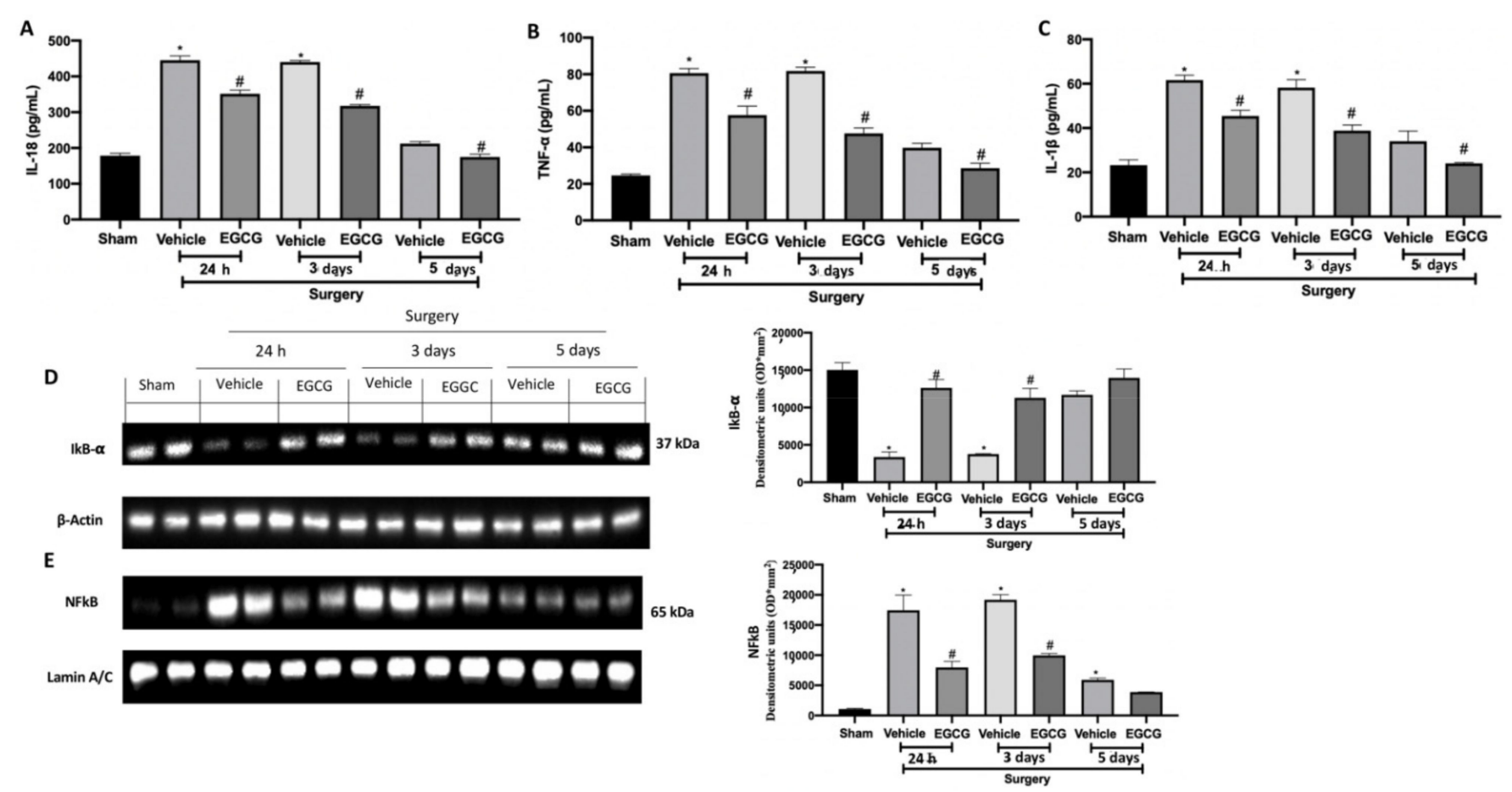

Figure 6. EGCG administration reduced cytokines and NFkB pathway activation: IL-18 (A), TNF- $\alpha$ (B), and IL-1 $\beta$ (C), Western blot analysis of: IkB- $\alpha$ (D) and NFkB (E) expression. A $p$-value of less than 0.05 was considered significant. ${ }^{*} p<0.05$ vs. sham, $\# p<0.05$ vs. vehicle.

\subsection{Effect of EGCG Administration on iNOS, COX-2 and PGE2 Expression Induced by PO Pain}

Western blot analysis showed increased iNOS and COX-2 expressions in tissues from vehicle treated rats $24 \mathrm{~h}$, and three and five days after surgery, as compared to sham animals. EGCG administration reduced both expressions at all timepoints (Figure 7A,B). Additionally, PGE2 levels were significantly increased $24 \mathrm{~h}$, and three and five days after surgery and EGCG administration reduced its levels (Figure 7C). 


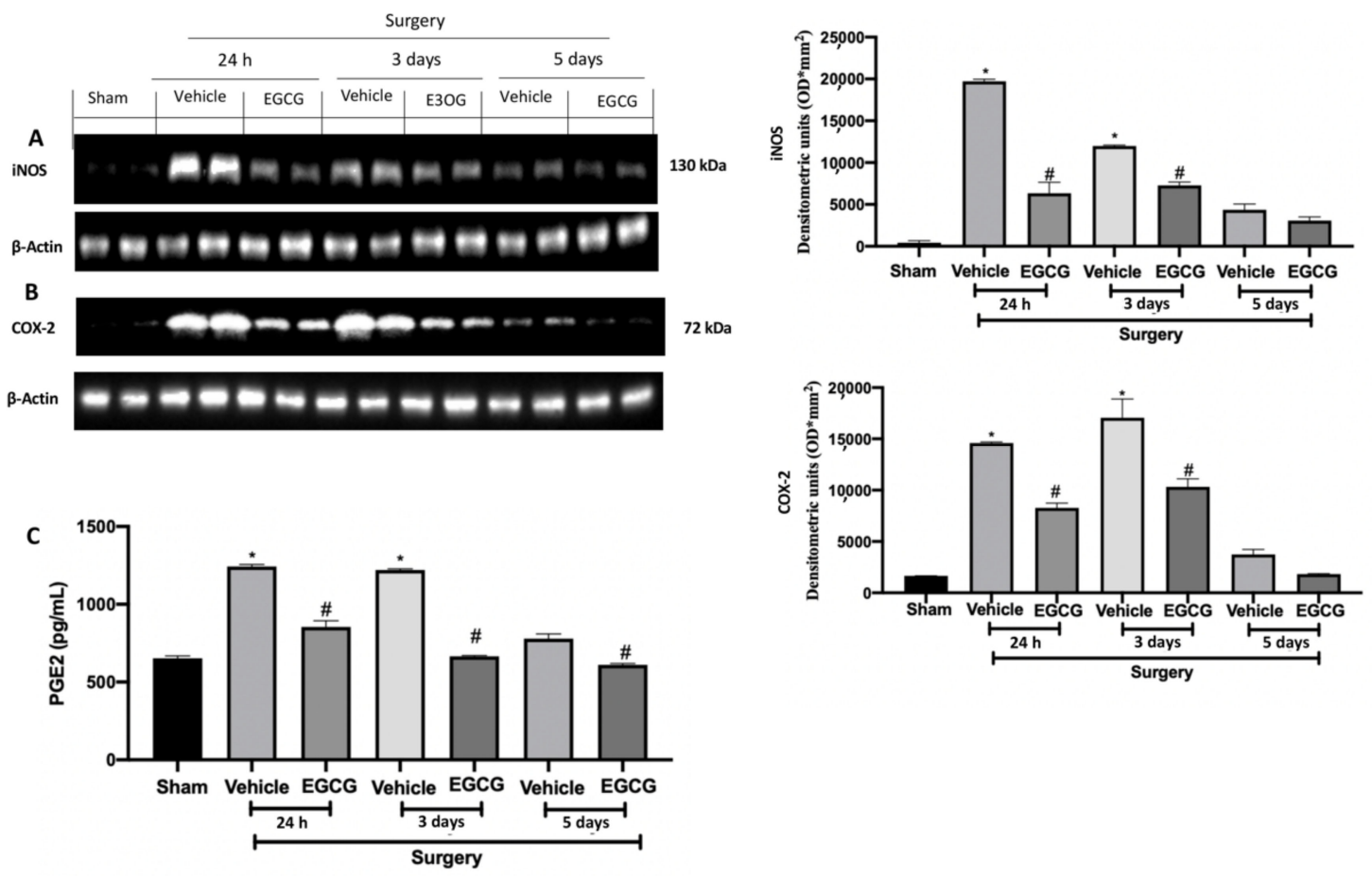

Figure 7. EGCG administration reduced iNOS, COX-2, and PGE2 expression: Western blot analysis of: iNOS (A), COX-2 (B) expression, PGE2 levels (C). A $p$-value of less than 0.05 was considered significant. ${ }^{*} p<0.05$ vs. sham, $\# p<0.05$ vs. vehicle.

\section{Discussion}

Patients consider PO pain to be one of the most unpleasant forms of surgical pain. Notwithstanding the increasing understanding of the molecular biology and neurology of PO pain, we still need to develop successful analgesics for pain control, including postoperative pain [32]. Thus, a significant number of patients continue to experience pain after surgery, which is not properly managed $[33,34]$. The surgical incision activates many molecular mechanisms that trigger and spread inflammation, oxidative stress and pain at peripheral and central levels $[7,35]$. This study was aimed to evaluate the mechanism of EGCG effect on PO pain in rats at different timepoints. EGCG showed important anti-inflammatory effects. In particular, mechanical hyperalgesia and thermal allodynia induced by the incision lasted for several days, while EGCG administration significantly alleviated hyperalgesia and allodynia. This antinociceptive would be ascribed to different molecular events induced by EGCG. We decided to evaluate the molecular mechanism activated by EGCG after $24 \mathrm{~h}$, and three and five days from surgery.

In particular, we investigated its effects on the WNT signaling pathway, evaluating the expression on WNT proteins. The $\beta$-catenin pathway is one of the most well studied in the propagation of pain and related injury and regeneration of the nervous system $[15,19,20]$. Among the 19 members of the WNT proteins family, WNT3a is the well-studied activator of this pathway [36,37]. Surgical incision induced an increase in the expression of WNT3a in the spinal cord. In particular, WNT3a expression was increased $24 \mathrm{~h}$ and three days from surgery, while after five days its expression partially decreased.

WNT3a binding to the FZ receptors induced the activation of the $W N T / \beta$-catenin signaling pathway in the postsynaptic neurons. EGCG reduced WNT3a expression and also managed the expression of the FZ receptors at all timepoints. In particular, EGCG decreased WNT3a expression already after $24 \mathrm{~h}$ and three days from the surgery. Among the FZ receptors the two most well studied in the pain perception are FZ1 and FZ8. They differ from each other for the contribution to pain production and persistence. In particular, FZ1 is rapidly but transiently increased after injury, while FZ8 over-expression lasted for longer, contributing to pain persistence [13]. EGCG administration reduced both FZ1 and FZ8 expression, reducing both pain production and persistence $24 \mathrm{~h}$, and three and 
five days from surgery. Activation of $W N T / \beta$-catenin signaling induces the $\beta$-catenin accumulation into the cytoplasm and its translocation into the nucleus [19,21]. EGCG once reduced the WNT3a and its receptor over expression also reduced $\beta$-catenin accumulation into the cytoplasm and translocation into the nucleus. From the neurochemical point of view $\mathrm{WNT} / \beta$-catenin signaling is responsible of the pain-induced activation of microglia and astrocytes cells and upregulated the expression of the NR2B receptor and the related Ca2+-dependent pathway in the dorsal horn of the spinal cord [11,13,38,39]. EGCG administration reduced pain perception as displayed by the behavioral analysis and acting on the $W N T / \beta$-catenin pathway, reduced GFAP and Iba- 1 over-expression both at all timepoints. Moreover, EGCG reduced the activation of the NMDA receptor subtype NR2B and the subsequent $\mathrm{Ca}^{2+}$-dependent signals Ppkc $\gamma$ and cAMP response element-binding protein (CREB) in the spinal cord at all timepoints. $\mathrm{PO}$ pain has also an important inflammatory component $[11,40]$. WNT/ $\beta$-catenin signaling regulates the IL-18 and TNF- $\alpha$ levels in the spinal cord that directly contribute to pain production and persistence. The increased expression of the pro-inflammatory cytokines is accompanied by elevation of IL-1 $\beta$ and NFkB pathway [41]. EGCG showed anti-inflammatory activity by reducing NFkB translocation into the nucleus and pro-inflammatory mediator over-expressions at all timepoints. NFkB manages the expression of several proteins such as COX-2 and iNOS [42]. COX-2, in turn, is major regulator of the increase in the PGE2 levels, which increases nociception following peripheral inflammatory stimuli. EGCG administration reduced COX-2 and iNOS expression and PGE2 levels $24 \mathrm{~h}$, and three and five days from surgery.

These results showed the important role of EGCG in modulating the WNT/ $\beta$-catenin signalling pathway suppressing the production and persistence of $\mathrm{PO}$ pain and the related neurochemical and inflammatory alterations.

\section{Materials and Methods}

\subsection{Animals}

Male Sprague Dawley rats (Envigo, Milan, Italy) were employed. This study was approved by the University of Messina Review Board for the care of animals (D.Lgs 2014/26 and EU Directive 2010/63).

\subsection{Surgical Procedures}

PO pain were performed as described previously [11]. Briefly, rats were anesthetized and placed dorsally. A $1 \mathrm{~cm}$ incision was made in the plantar hind paw. The underlying muscle was raised and longitudinally incised, leaving the insertion and origin of the muscle intact. A 5-0 nylon suture was employed to close the skin. The control group was anesthetized but no incision was performed.

\subsection{Experimental Groups}

Rats were randomly divided in groups:

Group 1: sham + vehicle: Rats were anesthetized but no incision was performed. Vehicle solution (distilled water) was administered one hour, six hours after anesthesia, and daily by gavage.

Group 2: sham + EGCG: Rats were anesthetized but no incision was performed. EGCG $(25 \mathrm{mg} / \mathrm{Kg})$ was administered one hour, six hours after anesthesia, and daily by gavage.

Group 3: PO pain + vehicle: Rats were subjected to surgical procedure and EGCG $(25 \mathrm{mg} / \mathrm{Kg})$ was administered one hour, six hours after surgery, and daily by gavage.

EGCG dose was chosen based on literature [43]. Behavioral analyses were performed daily and animals were sacrificed at $24 \mathrm{~h}$, and three and five days after surgery. Lumbar spinal cords were harvested for molecular analyses. 


\subsection{Behavioural Analysis}

\subsubsection{Mechanical Hyperalgesia}

A von Frey filament test was employed to evaluate hypersensitivity to a mechanic stimuli. The apparatus consists in a plastic box placed on a metal mesh floor and a force transducer equipped with a plastic tip [44-46]. After $15 \mathrm{~min}$ of acclimation the transducer was applied to the plantar surface until a sharp lift was observed. The mechanical threshold was recorded.

\subsubsection{Thermal Hyperalgesia}

A plantar test was employed to evaluate thermal hyperalgesia. The apparatus consists of plastic chambers and a mobile unit with a heat source $[47,48]$. After $15 \mathrm{~min}$ of habituation, the heat source was applied to the plantar surface and the paw withdrawal latency was recorded.

\subsubsection{Motor Coordination}

A rotarod test was employed to evaluate motor coordination. The apparatus consists of a horizontally oriented rotating cylinder suspended above a cage floor [49]. A training session was performed $24 \mathrm{~h}$ before test. The test was performed starting from a constant speed of $25 \mathrm{rpm}$, then the rotation was increased linearly at $20 \mathrm{rpm}$. The latency(s) for the first fall over a 4 min period was recorded.

\subsection{Immunohistochemical Analysis}

Lumbar spinal cord samples were fixed and embedded in paraffin. Immunohistochemical analysis was conducted, as previously described [50]. Sections were incubated overnight with: anti-glial fibrillary acidic protein GFAP (sc-33673) or anti-iba-1 (sc3272). All sections were washed with PBS and then treated, as previously reported [51,52]. Stained sections were observed using a Leica DM6 microscope (Leica Microsystems SpA, Milan, Italy) following a typical procedure [53].

\subsection{Western Blot Analysis}

Lumbar spinal cord tissues were homogenized and Western blots were performed as already described [54,55]. A specific primary antibody, such as WNT3a (sc-80457), anti-FZ1, anti-FZ8, anti- $\beta$-catenin, anti-active $\beta$-catenin, anti-pNR2B, anti- $\mathrm{pPKC} \gamma$, anti- $p$-CREB, anti-NFkB (sc-8008), anti-NOS2 (sc-7271), or anti-COX-2 (sc-376861), was mixed in 5\% $w / v$ nonfat dried milk solution and was incubated at $4{ }^{\circ} \mathrm{C}$ overnight. Afterwards, blots were incubated with peroxidase-conjugated bovine antimouse IgG secondary antibody or peroxidase conjugated goat anti-rabbit IgG for $1 \mathrm{~h}$ at room temperature [56,57]. To verify the equal amounts of protein, membranes were also incubated with the antibody against $\beta$-actin or lamin A/C. Signals were detected with enhanced chemiluminescence detection system reagent (Super-SignalWest Pico Chemiluminescent Substrate, Pierce, Monza, Italy) [58-60]. The relative expression of the protein bands was quantified by densitometry with Bio-Rad ChemiDoc XRS software (Bio-Rad, Milan, Italy) and standardized to $\beta$-actin or lamin A/C levels. Images of blot signals were imported to analysis software (v2003, Image Quant TL, Amersham Biosciences, Freiburg, Germany) [59]. The western blots analyses are representative of 3 different gels made by dividing the number of samples obtained from animals for each experimental group in different days [61,62].

\subsection{ELISA}

Serum IL-18, TNF- $\alpha$, IL-1 $\beta$ and PGE2 levels were measured by enzyme-linked immunosorbent assay (Cusabio Biotech), according to the manufacturer instructions in $\mathrm{pg} / \mathrm{mL}[63,64]$. 


\subsection{Statistical Evaluation}

All values in the figures and text are expressed as mean \pm standard error of the mean (SEM) of $\mathrm{N}$ observations. For in vivo studies, $\mathrm{N}$ represents the number of animals studied. The results were examined by one- or two-way analysis of variance followed by a Bonferroni post-hoc test for multiple comparisons. All results were normally distributed. A $p$-value of less than 0.05 was considered significant. A $p$-value of less than 0.05 was considered significant. ${ }^{*} p<0.05$ vs. sham, $\# p<0.05$ vs. vehicle.

Author Contributions: Conceptualization, R.S. and F.M.; methodology, D.I. and R.D.; software, M.C. and L.I.; validation, E.G.; formal analysis, R.C. and T.G.; investigation, A.F.P.; resources, R.F.; writingoriginal draft preparation, R.F.; writing-review and editing, R.D.P.; supervision, R.D.P.; project administration, S.C.; funding acquisition, S.C. All authors have read and agreed to the published version of the manuscript.

Funding: This research received no external funding.

Institutional Review Board Statement: The study was conducted according to the guidelines of the Declaration of Helsinki and approved by the Institutional Review Board for animal care (OPBA) of the University of Messina. (Protocol code number is 212/2021-PR, the date of the approval is 16 March 2021)

Informed Consent Statement: Not applicable.

Data Availability Statement: The data presented in this study are available on request from the corresponding author.

Conflicts of Interest: The authors declare no conflict of interest.

\section{References}

1. Phillips, D.M. JCAHO pain management standards are unveiled. Joint Commission on Accreditation of Healthcare Organizations. JAMA 2000, 284, 428-429. [CrossRef] [PubMed]

2. Gandhi, K.; Heitz, J.W.; Viscusi, E.R. Challenges in acute pain management. Anesthesiol. Clin. 2011, 29, 291-309. [CrossRef] [PubMed]

3. Kehlet, H.; Jensen, T.S.; Woolf, C.J. Persistent postsurgical pain: Risk factors and prevention. Lancet 2006, 367, 1618-1625. [CrossRef]

4. Kissin, I. The development of new analgesics over the past 50 years: A lack of real breakthrough drugs. Anesth. Analg. 2010, 110, 780-789. [CrossRef] [PubMed]

5. Dahl, J.B.; Kehlet, H. Treatment of postoperative pain-A status report. Ugeskr. Laeger. 2006, 168, 1986-1988. [PubMed]

6. Wu, C.L.; Raja, S.N. Treatment of acute postoperative pain. Lancet 2011, 377, 2215-2225. [CrossRef]

7. Brennan, T.J. Pathophysiology of postoperative pain. Pain 2011, 152, S33-S40. [CrossRef]

8. Pogatzki, E.M.; Gebhart, G.F.; Brennan, T.J. Characterization of Adelta- and C-fibers innervating the plantar rat hindpaw one day after an incision. J. Neurophysiol. 2002, 87, 721-731. [CrossRef]

9. Zahn, P.K.; Umali, E.; Brennan, T.J. Intrathecal non-NMDA excitatory amino acid receptor antagonists inhibit pain behaviors in a rat model of postoperative pain. Pain 1998, 74, 213-223. [CrossRef]

10. Brennan, T.J.; Vandermeulen, E.P.; Gebhart, G.F. Characterization of a rat model of incisional pain. Pain 1996, 64, 493-502. [CrossRef]

11. Siracusa, R.; Fusco, R.; Cordaro, M.; Peritore, A.F.; D'Amico, R.; Gugliandolo, E.; Crupi, R.; Genovese, T.; Evangelista, M.; Di Paola, R.; et al. The Protective Effects of Pre- and Post-Administration of Micronized Palmitoylethanolamide Formulation on Postoperative Pain in Rats. Int. J. Mol. Sci. 2020, 21, 7700. [CrossRef] [PubMed]

12. Zhu, Q.; Sun, Y.; Yun, X.; Ou, Y.; Zhang, W.; Li, J.X. Antinociceptive effects of curcumin in a rat model of postoperative pain. Sci. Rep. 2014, 4, 4932. [CrossRef]

13. Zhang, Y.K.; Huang, Z.J.; Liu, S.; Liu, Y.P.; Song, A.A.; Song, X.J. WNT signaling underlies the pathogenesis of neuropathic pain in rodents. J. Clin. Invest. 2013, 123, 2268-2286. [CrossRef] [PubMed]

14. Ciani, L.; Salinas, P.C. WNTs in the vertebrate nervous system: From patterning to neuronal connectivity. Nat. Rev. Neurosci. 2005, 6, 351-362. [CrossRef] [PubMed]

15. Packard, M.; Koo, E.S.; Gorczyca, M.; Sharpe, J.; Cumberledge, S.; Budnik, V. The Drosophila Wnt, wingless, provides an essential signal for pre- and postsynaptic differentiation. Cell 2002, 111, 319-330. [CrossRef]

16. Yang, K.; Wang, X.; Zhang, H.; Wang, Z.; Nan, G.; Li, Y.; Zhang, F.; Mohammed, M.K.; Haydon, R.C.; Luu, H.H.; et al. The evolving roles of canonical WNT signaling in stem cells and tumorigenesis: Implications in targeted cancer therapies. Lab. Invest. 2016, 96, 116-136. [CrossRef] 
17. Tu, X.; Joeng, K.S.; Nakayama, K.I.; Nakayama, K.; Rajagopal, J.; Carroll, T.J.; McMahon, A.P.; Long, F. Noncanonical Wnt signaling through $G$ protein-linked PKCdelta activation promotes bone formation. Dev. Cell 2007, 12, 113-127. [CrossRef]

18. Kestler, H.A.; Kuhl, M. Generating a Wnt switch: It's all about the right dosage. J. Cell Biol. 2011, 193, 431-433. [CrossRef]

19. Fuerer, C.; Nusse, R.; Ten Berge, D. Wnt signalling in development and disease. Max Delbruck Center for Molecular Medicine meeting on Wnt signaling in Development and Disease. EMBO Rep. 2008, 9, 134-138. [CrossRef] [PubMed]

20. Shimizu, H.; Julius, M.A.; Giarre, M.; Zheng, Z.; Brown, A.M.; Kitajewski, J. Transformation by Wnt family proteins correlates with regulation of beta-catenin. Cell Growth Differ. 1997, 8, 1349-1358.

21. Chen, J.; Park, C.S.; Tang, S.J. Activity-dependent synaptic Wnt release regulates hippocampal long term potentiation. J. Biol. Chem. 2006, 281, 11910-11916. [CrossRef]

22. Meng, J.M.; Cao, S.Y.; Wei, X.L.; Gan, R.Y.; Wang, Y.F.; Cai, S.X.; Xu, X.Y.; Zhang, P.Z.; Li, H.B. Effects and Mechanisms of Tea for the Prevention and Management of Diabetes Mellitus and Diabetic Complications: An Updated Review. Antioxidants 2019, 8, 170. [CrossRef]

23. Cooper, R.; Morre, D.J.; Morre, D.M. Medicinal benefits of green tea: Part I. Review of noncancer health benefits. J. Altern. Complement. Med. 2005, 11, 521-528. [CrossRef]

24. Min, K.J.; Kwon, T.K. Anticancer effects and molecular mechanisms of epigallocatechin-3-gallate. Integr. Med. Res. 2014, 3, 16-24. [CrossRef] [PubMed]

25. Du, G.J.; Zhang, Z.; Wen, X.D.; Yu, C.; Calway, T.; Yuan, C.S.; Wang, C.Z. Epigallocatechin Gallate (EGCG) is the most effective cancer chemopreventive polyphenol in green tea. Nutrients 2012, 4, 1679-1691. [CrossRef]

26. Minnelli, C.; Galeazzi, R.; Laudadio, E.; Amici, A.; Rusciano, D.; Armeni, T.; Cantarini, M.; Stipa, P.; Mobbili, G. Monoalkylated Epigallocatechin-3-gallate (C18-EGCG) as Novel Lipophilic EGCG Derivative: Characterization and Antioxidant Evaluation. Antioxidants 2020, 9, 208. [CrossRef]

27. Kim, H.S.; Quon, M.J.; Kim, J.A. New insights into the mechanisms of polyphenols beyond antioxidant properties; lessons from the green tea polyphenol, epigallocatechin 3-gallate. Redox. Biol. 2014, 2, 187-195. [CrossRef] [PubMed]

28. Bandele, O.J.; Osheroff, N. (-)-Epigallocatechin gallate, a major constituent of green tea, poisons human type II topoisomerases. Chem Res. Toxicol 2008, 21, 936-943. [CrossRef] [PubMed]

29. Sutherland, B.A.; Shaw, O.M.; Clarkson, A.N.; Jackson, D.N.; Sammut, I.A.; Appleton, I. Neuroprotective effects of (-)Epigallocatechin gallate following hypoxia-ischemia-induced brain damage: Novel mechanisms of action. Faseb. J. 2005, 19, 258-260. [CrossRef]

30. Zhou, J.; Mao, L.; Xu, P.; Wang, Y. Effects of (-)-Epigallocatechin Gallate (EGCG) on Energy Expenditure and Microglia-Mediated Hypothalamic Inflammation in Mice Fed a High-Fat Diet. Nutrients 2018, 10, 1681. [CrossRef]

31. Rasheed, Z.; Rasheed, N.; Al-Shaya, O. Epigallocatechin-3-O-gallate modulates global microRNA expression in interleukin1beta-stimulated human osteoarthritis chondrocytes: Potential role of EGCG on negative co-regulation of microRNA-140-3p and ADAMTS5. Eur. J. Nutr. 2018, 57, 917-928. [CrossRef] [PubMed]

32. Woolf, C.J. Overcoming obstacles to developing new analgesics. Nat. Med. 2010, 16, 1241-1247. [CrossRef] [PubMed]

33. Apfelbaum, J.L.; Chen, C.; Mehta, S.S.; Gan, T.J. Postoperative pain experience: Results from a national survey suggest postoperative pain continues to be undermanaged. Anesth. Analg. 2003, 97, 534-540. [CrossRef] [PubMed]

34. Phillips, C.; Gelesko, S.; Proffit, W.R.; White, R.P., Jr. Recovery after third-molar surgery: The effects of age and sex. Am. J. Orthod Dentofacial. Orthop. 2010, 138, 700.e1-700.e8. [CrossRef] [PubMed]

35. Watkins, L.R.; Maier, S.F.; Goehler, L.E. Immune activation: The role of pro-inflammatory cytokines in inflammation, illness responses and pathological pain states. Pain 1995, 63, 289-302. [CrossRef]

36. Liu, Y.; Wang, X.; Lu, C.C.; Kerman, R.; Steward, O.; Xu, X.M.; Zou, Y. Repulsive Wnt signaling inhibits axon regeneration after CNS injury. J. Neurosci. 2008, 28, 8376-8382. [CrossRef]

37. Suh, H.I.; Min, J.; Choi, K.H.; Kim, S.W.; Kim, K.S.; Jeon, S.R. Axonal regeneration effects of Wnt3a-secreting fibroblast transplantation in spinal cord-injured rats. Acta Neurochir. 2011, 153, 1003-1010. [CrossRef]

38. Liu, S.; Liu, W.T.; Liu, Y.P.; Dong, H.L.; Henkemeyer, M.; Xiong, L.Z.; Song, X.J. Blocking EphB1 receptor forward signaling in spinal cord relieves bone cancer pain and rescues analgesic effect of morphine treatment in rodents. Cancer Res. 2011, 71, 4392-4402. [CrossRef]

39. Wu, X.F.; Liu, W.T.; Liu, Y.P.; Huang, Z.J.; Zhang, Y.K.; Song, X.J. Reopening of ATP-sensitive potassium channels reduces neuropathic pain and regulates astroglial gap junctions in the rat spinal cord. Pain 2011, 152, 2605-2615. [CrossRef]

40. Fujita, I.; Okumura, T.; Sakakibara, A.; Kita, Y. Involvement of inflammation in severe post-operative pain demonstrated by pre-surgical and post-surgical treatment with piroxicam and ketorolac. J. Pharm. Pharmacol. 2012, 64, 747-755. [CrossRef]

41. Luchting, B.; Heyn, J.; Woehrle, T.; Rachinger-Adam, B.; Kreth, S.; Hinske, L.C.; Azad, S.C. Differential expression of P2X7 receptor and IL-1beta in nociceptive and neuropathic pain. J. Neuroinflammation 2016, 13, 100. [CrossRef]

42. Lee, K.M.; Kang, B.S.; Lee, H.L.; Son, S.J.; Hwang, S.H.; Kim, D.S.; Park, J.S.; Cho, H.J. Spinal NF-kB activation induces COX-2 upregulation and contributes to inflammatory pain hypersensitivity. Eur. J. Neurosci. 2004, 19, 3375-3381. [CrossRef] [PubMed]

43. Abo-Salem, O.M.; Ali, T.M.; Harisa, G.I.; Mehanna, O.M.; Younos, I.H.; Almalki, W.H. Beneficial effects of (-)-Epigallocatechin-3O-gallate on diabetic peripheral neuropathy in the rat model. J. Biochem. Mol. Toxicol. 2020, 34, e22508. [CrossRef] [PubMed] 
44. Fusco, R.; Siracusa, R.; D’Amico, R.; Peritore, A.F.; Cordaro, M.; Gugliandolo, E.; Crupi, R.; Impellizzeri, D.; Cuzzocrea, S.; Di Paola, R. Melatonin Plus Folic Acid Treatment Ameliorates Reserpine-Induced Fibromyalgia: An Evaluation of Pain, Oxidative Stress, and Inflammation. Antioxidants 2019, 8, 628. [CrossRef]

45. Cordaro, M.; Siracusa, R.; Impellizzeri, D.; R, D.A.; Peritore, A.F.; Crupi, R.; Gugliandolo, E.; Fusco, R.; Di Paola, R.; Schievano, C.; et al. Safety and efficacy of a new micronized formulation of the ALIAmide palmitoylglucosamine in preclinical models of inflammation and osteoarthritis pain. Arthritis Res. Ther. 2019, 21, 254. [CrossRef] [PubMed]

46. Fusco, R.; Siracusa, R.; Peritore, A.F.; Gugliandolo, E.; Genovese, T.; D'Amico, R.; Cordaro, M.; Crupi, R.; Mandalari, G.; Impellizzeri, D.; et al. The Role of Cashew (Anacardium occidentale L.) Nuts on an Experimental Model of Painful Degenerative Joint Disease. Antioxidants 2020, 9, 511. [CrossRef]

47. Gugliandolo, E.; D'Amico, R.; Cordaro, M.; Fusco, R.; Siracusa, R.; Crupi, R.; Impellizzeri, D.; Cuzzocrea, S.; Di Paola, R. Effect of PEA-OXA on neuropathic pain and functional recovery after sciatic nerve crush. J. Neuroinflammation 2018, 15, 264. [CrossRef]

48. Britti, D.; Crupi, R.; Impellizzeri, D.; Gugliandolo, E.; Fusco, R.; Schievano, C.; Morittu, V.M.; Evangelista, M.; Di Paola, R.; Cuzzocrea, S. A novel composite formulation of palmitoylethanolamide and quercetin decreases inflammation and relieves pain in inflammatory and osteoarthritic pain models. BMC Vet. Res. 2017, 13, 229. [CrossRef]

49. Impellizzeri, D.; Peritore, A.F.; Cordaro, M.; Gugliandolo, E.; Siracusa, R.; Crupi, R.; D'Amico, R.; Fusco, R.; Evangelista, M.; Cuzzocrea, S.; et al. The neuroprotective effects of micronized PEA (PEA-m) formulation on diabetic peripheral neuropathy in mice. Faseb. J. 2019, 33, 11364-11380. [CrossRef]

50. Di Paola, R.; Cordaro, M.; Crupi, R.; Siracusa, R.; Campolo, M.; Bruschetta, G.; Fusco, R.; Pugliatti, P.; Esposito, E.; Cuzzocrea, S. Protective Effects of Ultramicronized Palmitoylethanolamide (PEA-um) in Myocardial Ischaemia and Reperfusion Injury in VIVO. Shock 2016, 46, 202-213. [CrossRef]

51. Di Paola, R.; Fusco, R.; Gugliandolo, E.; D’Amico, R.; Campolo, M.; Latteri, S.; Carughi, A.; Mandalari, G.; Cuzzocrea, S. The Antioxidant Activity of Pistachios Reduces Cardiac Tissue Injury of Acute Ischemia/Reperfusion (I/R) in Diabetic Streptozotocin (STZ)-Induced Hyperglycaemic Rats. Front. Pharmacol. 2018, 9, 51. [CrossRef]

52. Fusco, R.; Gugliandolo, E.; Campolo, M.; Evangelista, M.; Di Paola, R.; Cuzzocrea, S. Effect of a new formulation of micronized and ultramicronized N-palmitoylethanolamine in a tibia fracture mouse model of complex regional pain syndrome. PLoS ONE 2017, 12, e0178553. [CrossRef]

53. Peritore, A.F.; Siracusa, R.; Fusco, R.; Gugliandolo, E.; D’Amico, R.; Cordaro, M.; Crupi, R.; Genovese, T.; Impellizzeri, D.; Cuzzocrea, S.; et al. Ultramicronized Palmitoylethanolamide and Paracetamol, a New Association to Relieve Hyperalgesia and Pain in a Sciatic Nerve Injury Model in Rat. Int. J. Mol. Sci. 2020, 21, 3509. [CrossRef] [PubMed]

54. Di Paola, R.; Impellizzeri, D.; Fusco, R.; Cordaro, M.; Siracusa, R.; Crupi, R.; Esposito, E.; Cuzzocrea, S. Ultramicronized palmitoylethanolamide (PEA-um((R))) in the treatment of idiopathic pulmonary fibrosis. Pharmacol. Res. 2016, 111, 405-412. [CrossRef]

55. Siracusa, R.; Fusco, R.; Peritore, A.F.; Cordaro, M.; D’Amico, R.; Genovese, T.; Gugliandolo, E.; Crupi, R.; Smeriglio, A.; Mandalari, G.; et al. The Antioxidant and Anti-Inflammatory Properties of Anacardium occidentale L. Cashew Nuts in a Mouse Model of Colitis. Nutrients 2020, 12, 834. [CrossRef] [PubMed]

56. Gugliandolo, E.; Fusco, R.; Ginestra, G.; D’Amico, R.; Bisignano, C.; Mandalari, G.; Cuzzocrea, S.; Di Paola, R. Involvement of TLR4 and PPAR-alpha Receptors in Host Response and NLRP3 Inflammasome Activation, Against Pulmonary Infection with Pseudomonas Aeruginosa. Shock 2019, 51, 221-227. [CrossRef]

57. Cuzzocrea, S.; Mazzon, E.; Esposito, E.; Muia, C.; Abdelrahman, M.; Di Paola, R.; Crisafulli, C.; Bramanti, P.; Thiemermann, C. Glycogen synthase kinase-3beta inhibition attenuates the development of ischaemia/reperfusion injury of the gut. Intensive Care Med. 2007, 33, 880-893. [CrossRef]

58. Gugliandolo, E.; Fusco, R.; D'Amico, R.; Peditto, M.; Oteri, G.; Di Paola, R.; Cuzzocrea, S.; Navarra, M. Treatment with a Flavonoid-Rich Fraction of Bergamot Juice Improved Lipopolysaccharide-Induced Periodontitis in Rats. Front. Pharmacol. 2018, 9 , 1563. [CrossRef]

59. Fusco, R.; Gugliandolo, E.; Biundo, F.; Campolo, M.; Di Paola, R.; Cuzzocrea, S. Inhibition of inflammasome activation improves lung acute injury induced by carrageenan in a mouse model of pleurisy. Faseb. J. 2017, 31, 3497-3511. [CrossRef] [PubMed]

60. D'Amico, R.; Fusco, R.; Gugliandolo, E.; Cordaro, M.; Siracusa, R.; Impellizzeri, D.; Peritore, A.F.; Crupi, R.; Cuzzocrea, S.; di Paola, R. Effects of a new compound containing Palmitoylethanolamide and Baicalein in myocardial ischaemia/reperfusion injury in vivo. Phytomedicine 2019, 54, 27-42. [CrossRef] [PubMed]

61. Cordaro, M.; Paterniti, I.; Siracusa, R.; Impellizzeri, D.; Esposito, E.; Cuzzocrea, S. KU0063794, a Dual mTORC1 and mTORC2 Inhibitor, Reduces Neural Tissue Damage and Locomotor Impairment After Spinal Cord Injury in Mice. Mol. Neurobiol. 2016, 54, 2415-2427. [CrossRef]

62. Siracusa, R.; Impellizzeri, D.; Cordaro, M.; Crupi, R.; Esposito, E.; Petrosino, S.; Cuzzocrea, S. Anti-Inflammatory and Neuroprotective Effects of Co-UltraPEALut in a Mouse Model of Vascular Dementia. Front. Neurol. 2017, 8, 233. [CrossRef] [PubMed] 
63. Mazzon, E.; Esposito, E.; Impellizzeri, D.; Di Paola, R.; Melani, A.; Bramanti, P.; Pedata, F.; Cuzzocrea, S. CGS 21680, an Agonist of the Adenosine (A2A) Receptor, Reduces Progression of Murine Type II Collagen-induced Arthritis. J. Rheumatol. 2011, 38, 2119-2129. [CrossRef] [PubMed]

64. Travelli, C.; Aprile, S.; Rahimian, R.; Grolla, A.A.; Rogati, F.; Bertolotti, M.; Malagnino, F.; di Paola, R.; Impellizzeri, D.; Fusco, R.; et al. Identification of Novel Triazole-Based Nicotinamide Phosphoribosyltransferase (NAMPT) Inhibitors Endowed with Antiproliferative and Antiinflammatory Activity. J. Med. Chem. 2017, 60, 1768-1792. [CrossRef] [PubMed] 